\title{
Trastuzumab beyond progression in patients with HER2-positive advanced gastric adenocarcinoma: a multicenter AGEO study
}

Juliette Palle ${ }^{1}$, David Tougeron ${ }^{2}$, Astrid Pozet $^{3}$, Emilie Soularue ${ }^{4}$ Pascal Artru $^{5}$, Florence Leroy 6 , Olivier Dubreuil7, Matthieu Sarabi, Nicolas Williet $^{9}$, Sylvain Manfredi ${ }^{10}$, Jerome Martin-Babau ${ }^{11}$, Christine Rebischung ${ }^{12}$, Meher Ben Abdelghani ${ }^{13}$, Ludovic Evesque ${ }^{14}$, Johann Dreanic ${ }^{15}$, Vincent Hautefeuille ${ }^{16}$, Samy Louafi $^{17}$, David Sefrioui ${ }^{18}$, Francesco Savinelli ${ }^{19}$, May Mabro ${ }^{20}$, Benoit Rousseau ${ }^{21}$, Cédric Lecaille ${ }^{22}$, Olivier Bouché ${ }^{23}$, Christophe Louvet ${ }^{24}$, Thierry Lecomte ${ }^{25}$, Franck Bonnetain ${ }^{3}$, Julien Taieb ${ }^{1,26}$ and Aziz Zaanan',26

${ }^{1}$ Department of Gastroenterology and Digestive Oncology, European Georges Pompidou Hospital, Assistance PubliqueHôpitaux de Paris, Paris, France

${ }^{2}$ Department of Gastroenterology, Poitiers University Hospital, Poitiers, France

${ }^{3}$ Methodology and Quality of Life in Oncology Unit, INSERM UMR 1098, Besançon University Hospital, Besançon, France

${ }^{4}$ Department of Medical Oncology, Saint Antoine Hospital, Assistance Publique-Hôpitaux de Paris, Paris, France

${ }^{5}$ Department of Gastroenterology and Digestive Oncology, Jean Mermoz Hospital, Lyon, France

${ }^{6}$ Department of Cancer Medicine, Gustave Roussy Institute, Villejuif, France

${ }^{7}$ Department of Gastroenterology and Digestive Oncology, Pitié-Salpêtrière Hospital, Assistance Publique-Hôpitaux de Paris, Paris, France

${ }^{8}$ Department of Medical Oncology, Léon Bérard Center, Lyon, France

${ }^{9}$ Department of Gastroenterology and Digestive Oncology, Saint-Etienne University Hospital, Saint-Priest en Jarez, France

${ }^{10}$ Department of Gastroenterology and Digestive Oncology, Rennes University Hospital, Rennes, France

${ }^{11}$ Department of Oncology, Morvan University Hospital, Brest, France

${ }^{12}$ Department of Oncology, Groupe Hospitalier Mutualiste of Grenoble, Grenoble, France

${ }^{13}$ Department of Oncology, Paul Strauss Center, Strasbourg, France

${ }^{14}$ Department of Oncology, Antoine Lacassagne Center, Nice, France

${ }^{15}$ Department of Gastroenterology and Digestive Oncology, Cochin Hospital, Assistance Publique-Hôpitaux de Paris, Paris, France

${ }^{16}$ Department of Gastroenterology and Digestive Oncology, Amiens University Hospital, Amiens, France

${ }^{17}$ Department of Oncology, Oncology Federation of Essonne, Essonne, France

${ }^{18}$ Department of Digestive Oncology, Rouen University Hospital, Rouen, France

${ }^{19}$ Department of Medical Oncology, Saint-Joseph Hospital, Paris, France

${ }^{20}$ Department of Oncology, Foch Hospital, Suresnes, France

${ }^{21}$ Department of Oncology, Henri Mondor Hospital, Assistance Publique-Hôpitaux de Paris, Créteil, France

${ }^{22}$ Department of Gastroenterology and Digestive Oncology, Polyclinique de Bordeaux Nord, Bordeaux, France

${ }^{23}$ Department of Gastroenterology and Digestive Oncology, Reims University Hospital, Reims, France

${ }^{24}$ Department of Medical Oncology, Mutualiste Montsouris Institute, Paris, France

${ }^{25}$ Department of Gastroenterology and Digestive Oncology, Trousseau University Hospital, Tours, France

${ }^{26}$ Paris Descartes University, Sorbonne Paris Cité, Paris, France

Correspondence to: Aziz Zaanan, email: aziz.zaanan@aphp.fr

Keywords: advanced gastric cancer; trastuzUmab; HER2; second-line chemotherapy; beyond progression

Received: March 01, $2017 \quad$ Accepted: August 05, $2017 \quad$ Published: September 08, 2017

Copyright: Palle et al. This is an open-access article distributed under the terms of the Creative Commons Attribution License 3.0 (CC BY 3.0), which permits unrestricted use, distribution, and reproduction in any medium, provided the original author and source are credited. 


\section{ABSTRACT}

Introduction: Trastuzumab in combination with platinum-based chemotherapy is the standard first-line regimen in HER2-positive advanced gastric cancer. However, there are very few data concerning efficacy of continuing trastuzumab beyond firstline progression.

Methods: This retrospective multicenter study included all consecutive patients with HER2-positive advanced gastric or gastro-esophageal junction (GEJ) adenocarcinoma who received a second-line of chemotherapy with or without trastuzumab after progression on platinum-based chemotherapy plus trastuzumab. Progression-free survival (PFS) and overall survival (OS) were estimated from the start of second-line chemotherapy using the Kaplan-Meier method and compared using log-rank test. The prognostic variables with $P$ values $\leq 0.05$ in univariate analysis were eligible for the Cox multivariable regression model.

Results: From May 2010 to December 2015, 104 patients were included (median age, 60.8 years; male, 78.8\%; ECOG performance status [PS] 0-1, $71.2 \%$ ). The continuation $(n=39)$ versus discontinuation $(n=65)$ of trastuzumab beyond progression was significantly associated with an improvement of median PFS (4.4 versus 2.3 months; $P=0.002$ ) and $0 S$ ( 12.6 versus 6.1 months; $P=0.001)$. In the multivariate analysis including the ECOG PS, number of metastatic sites and measurable disease, the continuation of trastuzumab beyond progression remained significantly associated with longer PFS (HR, 0.56; $95 \% \mathrm{CI}, 0.35-0.89 ; P=0.01)$ and OS (HR, 0.47; 95\% CI, 0.28-0.79; P=0.004).

Conclusion: This study suggests that continuation of trastuzumab beyond progression has clinical benefit in patients with HER2-positive advanced gastric cancer. These results deserve a prospective randomized validation.

\section{INTRODUCTION}

Gastric cancer is the fourth most commonly diagnosed cancer and the second most common cause of cancer-related deaths worldwide [1]. For patients with inoperable locally advanced or metastatic disease, systemic chemotherapy improves survival and quality of life compared with best supportive care alone [2]. In first-line treatment, doublet combination of platinum salts with fluoropyrimidine is considered as a standard of care $[3,4]$, and there remains controversy regarding the utility of adding anthracycline [5] or taxanes [6]. More recently, irinotecan-based chemotherapy has been suggested as a validated alternative therapy to platinum-based regimen $[7,8]$.

In HER2-positive advanced gastric or gastroesophageal junction (GEJ) adenocarcinoma, which accounts for approximately $10 \%$ to $30 \%$ of tumors [9], the randomized phase III ToGA trial demonstrated a significant improvement in progression-free survival (PFS) and overall survival (OS) with the addition of trastuzumab to cisplatin and fluoropyrimidine regimens (median OS: 13.8 versus 11.1 months; hazard ratio [HR], 0.74; 95\% confidence interval [CI], 0.60-0.91; $P=0.005$ ) [10]. Patients were eligible in this trial if their tumor samples were HER2-positive scored as $3+$ on immunohistochemistry (IHC) or if they were positive in fluorescence in situ hybridization (FISH) [10]. In pre- planned exploratory analysis, the survival benefit of trastuzumab was stronger in the HER2-positive subgroup with IHC $3+$ or $2+/$ FISH positive tumors (median OS: 16.0 versus 11.8 months; HR, 0.65 ; 95\% CI, $0.51-0.83$ ) [10]. More recently, two phase II studies have suggested that oxaliplatin was an interesting alternative drug instead of cisplatin in combination with fluoropyrimidine and trastuzumab [11, 12].

Nowadays, the strategy of second- and further-line treatment does not take into account the HER2 tumor status. In patients with an adequate condition status, second-line treatment may offer an improvement in OS and quality of life compared with best supportive care alone $[7,8]$. The validated therapeutic options include taxanes (docetaxel or paclitaxel) [13] and irinotecan alone [14] or combined with 5-FU (FOLFIRI regimen) [8], if not used before. A randomized phase III trial directly comparing paclitaxel versus irinotecan has demonstrated similar efficacy for both regimens [15]. More recently, two randomized phase III trials have demonstrated that ramucirumab was associated with a survival benefit as a single agent compared to best supportive care alone [16], whereas ramucirumab in addition to paclitaxel was associated with a survival benefit compared with paclitaxel alone [17].

From the first- to second-line treatment of cancer, the cytotoxic drugs are generally discontinued upon disease progression leading to change to another 
chemotherapy regimen. However, resistance to cytotoxic drugs is not always applicable to biologic agents, such as bevacizumab in metastatic colorectal cancer [18]. In HER2-positive advanced breast cancer, studies have shown that after failure of trastuzumab-containing therapy, the continuing of trastuzumab beyond progression in combination with another regimen of chemotherapy was associated with improvement of clinical outcomes [19, 20]. This interesting therapeutic strategy of continuing trastuzumab beyond progression has been little evaluated in gastric cancer. Thus, in this current study, we evaluate the efficacy of continuing trastuzumab after failure of first-line platinum-based chemotherapy plus trastuzumab in patients with HER2-positive advanced gastric or GEJ adenocarcinoma.

\section{RESULTS}

\section{Patient characteristics}

Among 278 patients with HER2-positive advanced gastric or GEJ adenocarcinoma treated in first-line treatment, we screened 151 patients who have received a second-line treatment between May 2010 and December 2015 (Figure 1). Among these 151 patients, we excluded patients who had received a second-line regimen other than those specified for this study $(n=16)$, and those for whom the evaluation of efficacy was not available $(n=10)$.
We also excluded patients who had received a nonplatinum first-line therapy $(n=15)$ or had stopped the firstline therapy for other cause than progression disease $(n=6)$ (Figure 1). The study population therefore consisted of 104 patients (median age, 60.8 years; male, 78.8\%; ECOG PS $0-1,71.2 \%$ ) with advanced (metastatic stage, 99\%) gastric $(45.2 \%)$ or GEJ $(54.8 \%)$ cancer (Table 1$)$. The median follow-up was 25.9 months (95\% CI, 16.4-30.8).

The trastuzumab was discontinued in second-line treatment for 65 patients $(62.5 \%)$ and continued for 39 patients $(37.5 \%)$. The most frequent second-line regimen was FOLFIRI (64.4\%), whatever the association or not with trastuzumab. All patients received first-line chemotherapy based on trastuzumab in combination with fluoropyrimidine and cisplatin $(51.9 \%)$ or oxaliplatin (48.1\%).

The clinical and pathological characteristics did not differ significantly between the two groups of discontinuation versus continuing trastuzumab in second-line treatment, except for the primary tumor site (GEJ, 38.5\% versus $82.1 \%$, respectively; $P<0.0001$ ) and the number of metastatic sites $(\geq 2$ metastatic sites, $76.9 \%$ versus $56.4 \%$, respectively; $P=0.03$ ) (Table 1 ). In addition, for patients who continued trastuzumab beyond progression, a first-line of oxaliplatin-based chemotherapy was more frequently administered (74.4\%) than cisplatinbased chemotherapy $(25.6 \%)(P<0.0001)$ (Table 1$)$.

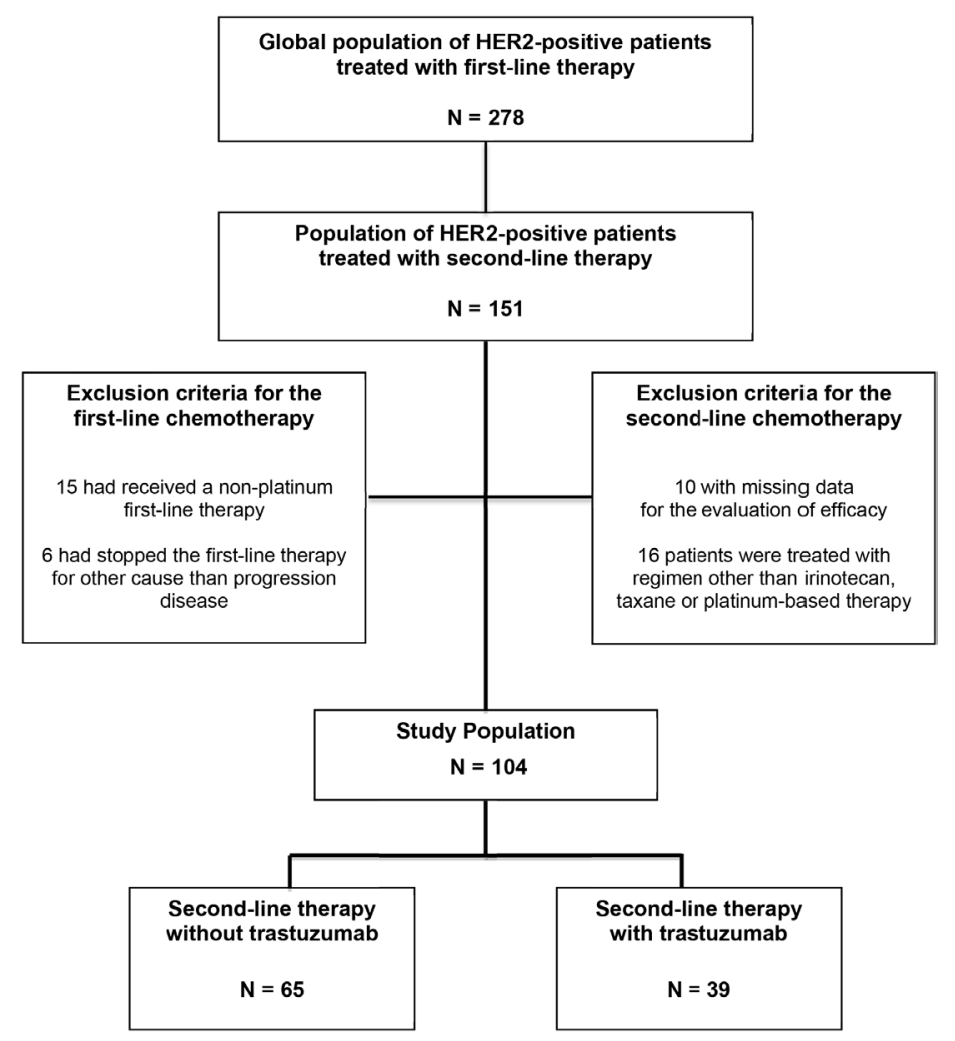

Figure 1: Flow Chart of study. 
Table 1: Clinical and pathological characteristics at baseline of the second-line of chemotherapy

\begin{tabular}{|c|c|c|c|c|}
\hline & Overall Population & $\begin{array}{l}\text { Second-line therapy } \\
\text { without trastuzumab }\end{array}$ & $\begin{array}{l}\text { Second-line therapy } \\
\text { with trastuzumab }\end{array}$ & P-value \\
\hline & $N=104$ & $N=65$ & $\mathbf{N}=\mathbf{3 9}$ & \\
\hline Age & & & & 0.41 \\
\hline Mean & 60.0 & 61.3 & 57.9 & \\
\hline Median [range] & $60.8[17.3-80.3]$ & $59.0[34.0-80.3]$ & $61.1[17.3-80.1]$ & \\
\hline Gender & & & & 0.53 \\
\hline Male & $82(78.8 \%)$ & $50(76.9 \%)$ & $32(82.1 \%)$ & \\
\hline Female & $22(21.2 \%)$ & $15(23.1 \%)$ & $7(17.9 \%)$ & \\
\hline ECOG PS & & & & 0.81 \\
\hline $0-1$ & $74(71.2 \%)$ & $45(69.2 \%)$ & $29(74.4 \%)$ & \\
\hline$\geq 2$ & $23(22.1 \%)$ & $15(23.1 \%)$ & $8(20.5 \%)$ & \\
\hline Unknown & $7(6.7 \%)$ & $5(7.7 \%)$ & $2(5.1 \%)$ & \\
\hline Primary tumor site & & & & $<0.0001$ \\
\hline $\begin{array}{l}\text { Gastro-esophageal } \\
\text { junction }\end{array}$ & $57(54.8 \%)$ & $25(38.5 \%)$ & $32(82.1 \%)$ & \\
\hline Stomach & $47(45.2 \%)$ & $40(61.5 \%)$ & $7(17.9 \%)$ & \\
\hline Histological type & & & & 0.06 \\
\hline Intestinal & $54(51.9 \%)$ & $34(52.3 \%)$ & $20(51.3 \%)$ & \\
\hline Diffuse or mixed & $12(11.6 \%)$ & $4(6.2 \%)$ & $8(20.5 \%)$ & \\
\hline Other or unknown & $38(36.5 \%)$ & $27(41.5 \%)$ & $11(28.2 \%)$ & \\
\hline Tumor grade & & & & 0.41 \\
\hline $\begin{array}{l}\text { Well/Moderately } \\
\text { differentiated }\end{array}$ & $63(60.6 \%)$ & $37(56.9 \%)$ & $26(66.7 \%)$ & \\
\hline Poorly differentiated & $29(27.9 \%)$ & $21(32.3 \%)$ & $8(20.5 \%)$ & \\
\hline Unknown or missing & $12(11.5 \%)$ & $7(10.8 \%)$ & $5(12.8 \%)$ & \\
\hline Extent of disease & & & & 0.15 \\
\hline Locally advanced & $1(1.0 \%)$ & $0(0 \%)$ & $1(2.5 \%)$ & \\
\hline Metastatic & $103(99.0 \%)$ & $65(100 \%)$ & $38(97.5 \%)$ & \\
\hline Measurable disease & $91(87.5 \%)$ & $55(84.6 \%)$ & $36(92.3 \%)$ & 0.32 \\
\hline $\begin{array}{l}\text { Number of metastatic } \\
\text { sites }\end{array}$ & & & & 0.03 \\
\hline $0-1$ & $32(30.8 \%)$ & $15(23.1 \%)$ & $17(43.6 \%)$ & \\
\hline$\geq 2$ & $72(69.2 \%)$ & $50(76.9 \%)$ & $22(56.4 \%)$ & \\
\hline HER2 status & & & & 0.16 \\
\hline IHC $3+$ & $83(79.8 \%)$ & $49(75.4 \%)$ & $34(87.2 \%)$ & \\
\hline IHC 2+/FISH-positive & $17(16.4 \%)$ & $14(21.5 \%)$ & $3(7.7 \%)$ & \\
\hline Unknown & $4(3.8 \%)$ & $2(3.1 \%)$ & $2(5.1 \%)$ & \\
\hline
\end{tabular}

(Continued) 


\begin{tabular}{lcccc}
\hline & Overall Population & $\begin{array}{c}\text { Second-line therapy } \\
\text { without trastuzumab }\end{array}$ & $\begin{array}{c}\text { Second-line therapy } \\
\text { with trastuzumab }\end{array}$ & P-value \\
\cline { 2 - 4 } & $\mathbf{N}=\mathbf{1 0 4}$ & $\mathbf{N}=\mathbf{6 5}$ & $\mathbf{N}=\mathbf{3 9}$ & $<0.0001$ \\
\hline $\begin{array}{l}\text { First-line chemotherapy } \\
\text { regimen }\end{array}$ & & & \\
$\begin{array}{l}\text { FP + oxaliplatin } \\
\text { trastuzumab }\end{array}$ & $50(48.1 \%)$ & $21(32.3 \%)$ & $29(74.4 \%)$ \\
$\begin{array}{l}\text { FP + cisplatin } \\
\text { trastuzumab }\end{array}$ & $54(51.9 \%)$ & $44(67.7 \%)$ & $10(25.6 \%)$ \\
$\begin{array}{l}\text { Second-line } \\
\text { chemotherapy regimen }\end{array}$ & & & \\
FOLFIRI & $67(64.4 \%)$ & $48(73.9 \%)$ & $19(48.7 \%)$ \\
Taxane & $23(22.1 \%)$ & $11(16.9 \%)$ & $12(30.8 \%)$ \\
FP + platinum salts & $14(13.5 \%)$ & $6(9.2 \%)$ & $8(20.5 \%)$ \\
\hline
\end{tabular}

Abbreviations: IHC, immunohistochemistry; FISH, fluorescence in-situ hybridization; FP, Fluoropyrimidine

The other patient characteristics are summarized in Table 1. We observed a trend toward longer median PFS (HR, 0.76; 95\% CI, 0.51-1.13; $P=0.18$ ) and a significant higher objective response rate (ORR) (57\% versus $24 \%$; $P=0.001)$ in first-line treatment for patients who have continued as compared with those who have discontinued trastuzumab beyond progression.

\section{Tumor response}

Tumor response was evaluated in 91 patients $(87.5 \%)$ who had measurable disease. In the overall population, the ORR and disease control rate (DCR) in second-line treatment were $9.9 \%$ and $36.3 \%$, respectively (Table 2). In comparison with patients who stopped trastuzumab in second-line chemotherapy, those who continued it had a trend toward higher ORR $(16.7 \%$ versus $5.4 \% ; P=0.08)$ and a significantly higher DCR $(50.0 \%$ versus $27.3 \%$; $P=0.03$ ) (Table 2).

\section{Progression-free survival}

In the overall population, 98 (94.2\%) patients had tumor progression or died from the start of second-line chemotherapy until the end of follow-up. The median PFS was 2.7 months (95\% CI, 2.3-4.0), and the 6-months PFS rate was $20.8 \%$ (95\% CI, 13.5-29.3) (Table 2). The continuation of trastuzumab in second-line chemotherapy was significantly associated with an improvement of median PFS as compared to trastuzumab discontinuation (4.4 versus 2.3 months; $P=0.002$ ) (Figure $2 \mathrm{~A}$ ).

In univariate analysis, trastuzumab beyond progression, ECOG PS, measurable disease and the number of metastatic sites were significantly associated with PFS (Table 3). In multivariate analysis, the following factors remained significantly associated with longer PFS: trastuzumab in second-line chemotherapy (with versus without: HR, 0.56; 95\% CI, 0.35-0.89; $P=0.01)$, ECOG PS ( $0-1$ versus 2 : $\mathrm{HR}, 0.56$; $95 \% \mathrm{CI}, 0.34-0.91 ; P=0.02)$ and measurable disease (yes versus no: HR, $0.42 ; 95 \% \mathrm{CI}$, 0.21-0.85; $P=0.01$ ) (Table 3).

\section{Overall survival}

In the overall population, $83(79.8 \%)$ patients had died from the start of second-line chemotherapy until the end of follow-up. The median OS was 7.1 months (95\% CI, 5.5-9.4), and the 1-year OS rate was $29.1 \%(95 \% \mathrm{CI}$, 19.9-38.9) (Table 2). The continuation of trastuzumab in second-line chemotherapy was significantly associated with an improvement of median OS as compared to trastuzumab discontinuation (12.6 versus 6.1 months; $P=0.001$ ) (Figure 2B).

In addition to trastuzumab beyond progression, ECOG PS, measurable disease and the number of metastatic sites were significantly associated with OS in the univariate analysis (Table 3). In multivariate analysis, we observed that the following factors remained significantly associated with longer OS: trastuzumab in second-line chemotherapy (with versus without: HR, 0.47; $95 \%$ CI, $0.28-0.79 ; P=0.004)$, ECOG PS ( $0-1$ versus 2 : HR, $0.34 ; 95 \%$ CI, $0.20-0.57 ; P<0.0001)$ and measurable disease (yes versus no: HR, $0.39 ; 95 \% \mathrm{CI}, 0.19-0.79$; $P=0.009$ ) (Table 3).

\section{DISCUSSION}

In this large multicenter study of HER2-positive gastric cancer, we observed in patients with disease progression after trastuzumab-containing platinum-based 
Table 2: Analysis of tumor response and survival according to the continuation or not of trastuzumab from the second-line of chemotherapy

$\begin{array}{cccc}\text { Overall Population } & \begin{array}{c}\text { Second-line therapy } \\ \text { without trastuzumab }\end{array} & \begin{array}{c}\text { Second-line therapy } \\ \text { with trastuzumab }\end{array} & P \text {-value } \\ \mathrm{N}=\mathbf{1 0 4} & \mathrm{N}=\mathbf{6 5} & \mathrm{N}=39 & \end{array}$

\begin{tabular}{lcccc} 
Tumor response & & & \\
Complete response & $3(2.9 \%)$ & $1(1.5 \%)$ & $2(5.1 \%)$ & \\
Partial response & $6(5.7 \%)$ & $2(3.1 \%)$ & $4(10.3 \%)$ & \\
Stable disease & $24(23.1 \%)$ & $12(18.5 \%)$ & $12(30.8 \%)$ & \\
Progression disease & $58(55.8 \%)$ & $40(61.5 \%)$ & $18(46.1 \%)$ & 0.08 \\
Not evaluable & $13(12.5 \%)$ & $10(15.4 \%)$ & $3(7.7 \%)$ & 0.03 \\
Objective response rate * & $9.9 \%$ & $5.4 \%$ & $16.7 \%$ & 0.002 \\
Disease control rate * & $36.3 \%$ & $27.3 \%$ & $50.0 \%$ & 0.001 \\
Median PFS, mo. (95\% CI) & $2.7(2.3-4.0)$ & $2.3(2.0-3.0)$ & $30.2 \%(16.4-5.6)$ & $12.6(5.5-18.5)$ \\
6-mo. PFS rate (95\% CI) & $20.8 \%(13.5-29.3)$ & $13.5 \%(6.5-23.1)$ & $48.4 \%(29.8-64.7)$ & \\
Median OS, mo. (95\% CI) & $7.1(5.5-9.4)$ & $6.1(4.8-8.3)$ & $17.9 \%(9.3-28.8)$ & \\
1-yr OS rate (95\% CI) & $29.1 \%(19.9-38.9)$ & & & \\
\hline
\end{tabular}

* Objective response rate and disease control rate were evaluated in patients who had measurable disease ( $\mathrm{n}=91$ ).

The $\mathrm{P}$ values for comparison of objective response and disease control rates were assessed using the Chi2 test.

The $\mathrm{P}$ value for the comparison of time to event endpoints was assessed using the log-rank test.

Abbreviations: mo., months; yr, year

therapy that changing chemotherapy with continuation of trastuzumab was associated with improved clinical outcomes. Patients who continued trastuzumab in secondline treatment had a better ORR, and a significantly longer PFS and OS than those who stopped trastuzumab. Our data support the concept of continuing trastuzumab beyond first-line progression in HER2-positive gastric cancer, as was already demonstrated in HER2-positive breast cancer $[19,20]$.
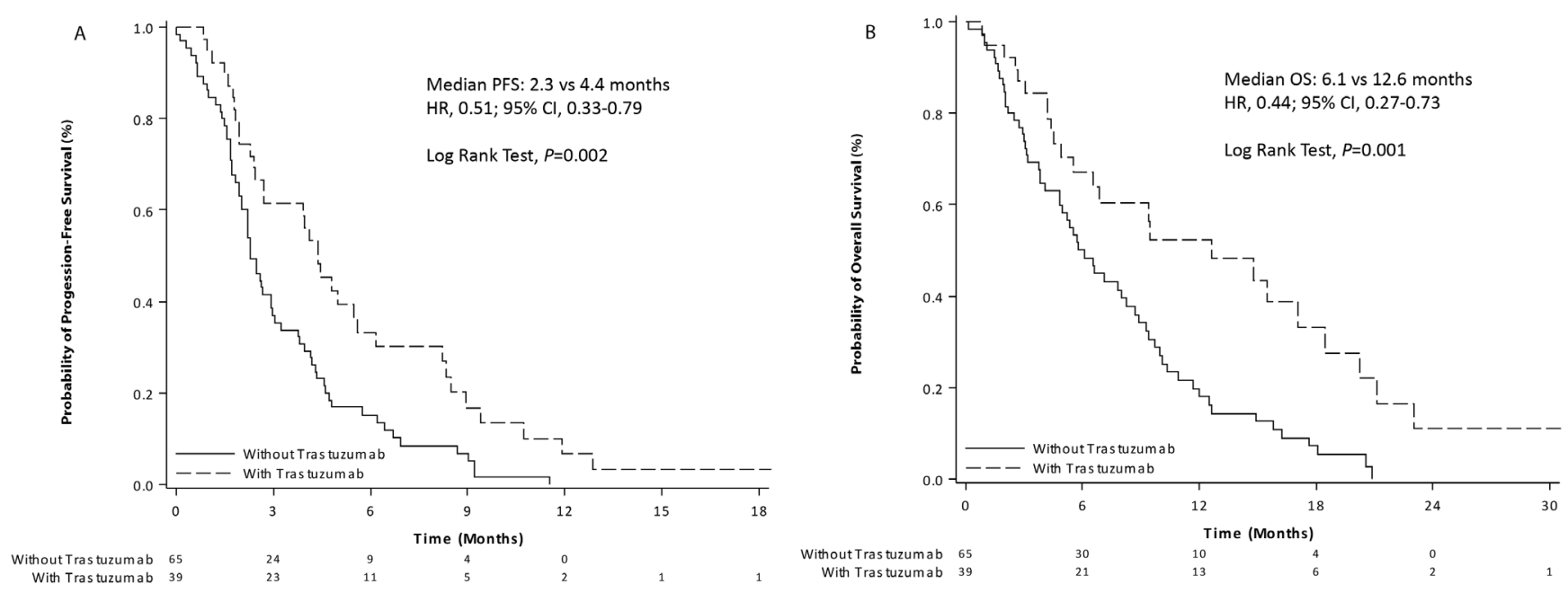

Figure 2: Kaplan-Meier curves of progression-free survival (A) and overall survival (B) from the start of second-line chemotherapy with (dashed line) or without (solid line) trastuzumab in patients with HER2-positive advanced gastric or gastro-esophageal junction adenocarcinoma. 
Table 3: Univariate and multivariate analysis for progression-free survival and overall survival from the second-line of chemotherapy

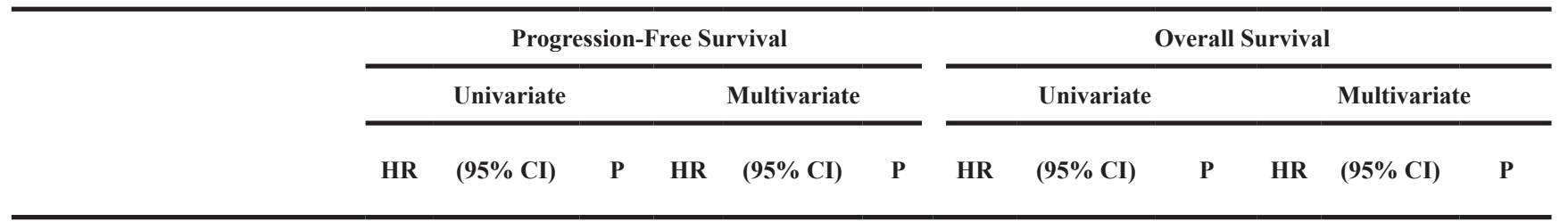

Age (years)

$\begin{array}{lllllll}\leq 60 \mathrm{vs}>60^{\mathrm{R}} & 0.85 & (0.57-1.27) & 0.43 & 1.18 & (0.76-1.82) & 0.44\end{array}$

Gender
Male vs female ${ }^{\mathrm{R}}$
$0.65 \quad(0.40-1.05) \quad 0.08$
$0.62 \quad(0.37-1.03) \quad 0.06$

ECOG performance status
$0-1$ vs $\geq 2^{R}$
0.52
$(0.32-0.86)$
0.009
0.56
$(0.34-0.91) \quad 0.02$
0.35
$(0.21-0.59) \quad<.0001$
0.34
$(0.20-0.57) \quad<.0001$

Primary tumor site

Junction vs stomach ${ }^{\mathrm{R}}$

$0.76 \quad(0.50-1.13) \quad 0.18$

$0.70 \quad(0.45-1.09)$

0.11

Histological type

Diffuse/mixed vs intestinal ${ }^{\mathrm{R}}$

$1 \quad(0.53-1.90) \quad 0.99$

$0.82 \quad(0.41-1.63) \quad 0.57$

Tumor grade

Well/moderate vs poor ${ }^{\mathrm{R}}$

$0.69 \quad(0.46-1.05) \quad 0.09$

$0.57 \quad(0.35-0.93) \quad 0.06$

Measurable disease

Yes vs No ${ }^{\mathrm{R}}$

0.36

$\begin{array}{lll}(0.19-0.67) & 0.001 & 0.42\end{array}$

(0.21-0.85)

0.01

0.36

$(0.19-0.67)$

0.001

0.39

$(0.19-0.79) \quad 0.009$

Number of metastatic sites

$0-1 \mathrm{vs} \geq 2^{\mathrm{R}}$

0.63

$(0.40-1.0) \quad 0.049 \quad 0.70$

(0.43-1.13)

0.14

0.61

$(0.37-0.99)$

0.048

$0.59 \quad(0.34-1.02) \quad 0.06$

Second-line chemotherapy

With vs without trastuzumab ${ }^{\mathrm{R}}$

0.51

$\begin{array}{lll}(0.33-0.79) & 0.002 & 0.56\end{array}$

$(0.35-0.89) \quad 0.01$

0.44

$(0.27-0.73)$

0.002

0.47

$(0.28-0.79) \quad 0.004$

Abbreviations: R, reference; HR, hazard ratio; ECOG, Eastern Cooperative Oncology Group; PFS, progression-free survival; OS, overall survival. Multivariate analysis was performed on variables potentially predictive of the risk of disease progression or death in univariate analysis (threshold, $5 \%$ ). For PFS and OS multivariate analysis, 7 patients were excluded because they had at least one missing data among the variables selected on univariate analysis; finally, 97 patients were selected for multivariate analysis.

A $P$ value $<0.05$ was considered statistically significant. 
There are some clinical data about second-line antiHER2 therapies, but these studies were not dedicated to patients pretreated with trastuzumab. The TYTAN randomized phase III trial evaluated the efficacy of paclitaxel with or without lapatinib, a dual inhibitor of EGFR and HER2 tyrosine kinase activity, as secondline treatment in patients with HER2 FISH-positive tumors [21]. The addition of lapatinib to paclitaxel was not associated with an improvement of either PFS or OS [21]. In this trial, only $6 \%$ of patients received a prior treatment with trastuzumab. Lapatinib was also evaluated in first-line treatment in HER2 FISH-positive tumors in the LOGIC phase III trial comparing capecitabineoxaliplatin (CAPOX) with or without lapatinib [22]. The addition of lapatinib to CAPOX did not significantly increase survival, even in patients with $\mathrm{IHC} 3+$ or IHC2+/ FISH-positive tumors [22]. The GATSBY study is another randomized trial evaluating trastuzumab emtasine ( $\mathrm{T}$ DM1) versus taxane in second-line treatment of patients with HER2-positive tumors defined by IHC3+ or IHC2+/ FISH-positive [23]. This study did not show a superiority of T-DM1 over taxane in terms of PFS and OS, regardless of whether or not the first-line treatment included trastuzumab [23]. Therefore, in contrast to HER2-positive breast cancer [20], trastuzumab remains the only antiHER2 therapy validated in HER2-positive gastric cancer. Further elucidation of HER2 biology is needed to shed light on differences in terms of efficacy of anti-HER2 therapies between gastric and breast cancers.

Recently, $\mathrm{Li}$ et al evaluated the efficacy of trastuzumab beyond progression in a prospective observational cohort of 59 Chinese patients with HER2positive advanced gastric cancer [24]. This study showed that continuing trastuzumab in combination with chemotherapy versus chemotherapy alone was associated with an improvement of PFS, while tumor response rate and OS were not significantly improved [24]. All patients received trastuzumab in combination with a first-line chemotherapy. However, in this relatively small Asian series, more than half of the patients received a nonplatinum drug in first-line therapy, and approximately one-third received a platinum drug in second-line, which makes it difficult to interpret the real value of trastuzumab beyond progression after failure of standard platinumbased treatment. In 2017, Makiyama et al. presented at the ASCO GI meeting, an observational study of 85 patients from Japan treated with continuation $(n=59)$ or not $(n=25)$ of trastuzumab in second-line treatment. In this study, the trastuzumab beyond progression strategy was significantly associated with an increase of median OS (12.8 versus 7.9 months; HR, 0.50; 95\% CI 0.29-0.84; $P=0.01$ ), although very poor data were given regarding the first-line treatment [25]. In addition, there is currently an ongoing randomized phase II study in Japan (WJOG7112G) comparing trastuzumab in combination with weekly paclitaxel versus weekly paclitaxel alone after failure of a trastuzumab, fluoropyrimidine and platinum containing chemotherapy (UMIN-CTR Clinical Trial ID: UMIN000009297).

In our study, the choice of second-line chemotherapy regimen was left to clinician's discretion. We observed that patients were more frequently treated with FOLFIRI $(64.4 \%)$ than taxane $(22.1 \%)$ in second-line chemotherapy. This finding is probably related to neuropathy induced by the first-line platinum-based chemotherapy, resulting in a limitation of taxane-based second-line treatment that also induces neuropathy. This toxicity profile may have introduced a bias in the decision to continue trastuzumab beyond progression since trastuzumab is readily combined with taxane in breast cancer, while data on combining FOLFIRI with trastuzumab are lacking. A minority of patients received a platinum-based second-line chemotherapy $(n=14,13.5 \%)$ with a different compound from that used in first-line (11 were treated with oxaliplatin after cisplatin and 3 with cisplatin after oxaliplatin). A phase II study has suggested that oxaliplatin might reverse resistance to cisplatin in gastric cancer treatment [26]. However, the synergic effect of trastuzumab beyond progression by changing the platinum salts used in first line was not evaluated in our study due to the low number of patients included in these subgroups. Of note no cardiac toxicity was reported in trastuzumab beyond progression group during the time of the study.

We observed in our study that the response rate in first-line was higher for patients treated with trastuzumab beyond progression. A better comprehension of the mechanisms leading to trastuzumab sensibility or resistance is needed to identify the patients who would benefit from continuation of trastuzumab beyond progression. Preclinical studies have suggested that activation of alternative tyrosine kinase receptors (such as EGFR, HER3, FGFR2 and MET) or signaling pathways (such as Src and Notch1), often leading to epithelial-mesenchymal transition, could lead to secondary resistance to trastuzumab [27]. Micro RNAs have also been pointed out as a potential actor in primary and secondary resistance to HER2-targetting therapy [28]. Moreover, the direct loss of HER2 overexpression or amplification have been reported after exposition to trastuzumab containing therapy $[29,30]$, raising the question of the interest of new biopsies at disease progression.

Despite the low rate of missing data (under 10\%), the main limitation of our study is its retrospective nature and the small series of patients. Patients in the group receiving second-line chemotherapy without trastuzumab had more frequently $\geq 2$ metastatic sites than patients who continued trastuzumab beyond progression. This might suggest that patients without trastuzumab in second-line treatment had initially more aggressive disease. Nevertheless, in the multivariate analysis including these variables (Table 3), the HR for PFS and OS was still significantly in favor of continuation of trastuzumab beyond progression. Another limitation is the small number of patients in each treatment subgroup that not allow us to evaluate which regimen of 
second-line chemotherapy was the most effective with trastuzumab beyond progression.

\section{MATERIALS AND METHODS}

\section{Patients}

This retrospective multicenter non-interventional study included, in 24 French care centers, all consecutive patients with histologically proven HER2-positive advanced (locally advanced or metastatic) gastric or GEJ adenocarcinoma who after progression on trastuzumab plus platinum-based therapy received from May 2010 to December 2015 a second-line chemotherapy with irinotecan, taxane or platinum-based therapy, with or without trastuzumab. We excluded patients who had stopped first-line chemotherapy for reasons other than disease progression. The HER2-positive tumor was defined as IHC $3+$ or IHC 2+/FISH-positive status. This study was approved by the Pitié Salpêtrière Hospital ethics committee (CPP - Ile-de-France, Paris VI), and was conducted in agreement with the appropriate ethical guidelines and legislation.

\section{Treatment and Outcome}

The choices of second-line chemotherapy regimen and the decision to continue trastuzumab or not were left to the physician's discretion. Chemotherapy was continued until disease progression or limiting toxicity. Routine clinical, laboratory and CT scan follow-up was performed every 2 or 3 months according to physician and local practice, or earlier if progression was suspected. Tumor response was assessed by CT scans in patients with measurable disease based on RECIST criteria (version 1.1) (patients without measurable disease were evaluated for PFS and OS only).

By reviewing of medical records, data were collected on relevant clinical and tumor characteristics, chemotherapy regimen received on first and second line, tumor response, date of disease progression and survival status at the last follow-up. The data were updated in June 2016.

\section{Statistical analyses}

The main objective of this study was to evaluate the impact on PFS of continuing or not trastuzumab in second-line chemotherapy. Baseline clinical and pathological characteristics were compared according to the continuation or not of trastuzumab in secondline chemotherapy. Continuous variable were described as means, standard deviation, median and range, and compared using Student test or Wilcoxon test in case of normal distribution or not, respectively. Qualitative variables were described as frequencies and percentages and compared using the $\chi 2$ test or Fisher's exact test as appropriate. The median follow-up was estimated using the reverse Kaplan-Meier method.

Progression-free survival was defined as the time elapsed from the first cycle of second-line chemotherapy until the date of first progression or death (all causes), whichever came first. Alive patients without disease progression were censored at the last follow-up date. Overall survival was defined as the time elapsed from the first cycle of second-line chemotherapy until death (all causes). Alive patients were censored on the last follow-up date. Survival curves were estimated using the Kaplan-Meier method and compared using the log-rank test. Cox univariate and multivariate analysis were used to calculate HR with a 95\% CI. The variables with $P$ values $\leq 0.05$ in univariate analysis were eligible for the Cox multivariable regression model. The assumption of risks proportionality and log-linearity were verified for each variable. Correlations between all variables were explored. In case of strong correlation between two variables, either one variable was included in the multivariate model.

A $P$ value of less than 0.05 was considered statistically significant. All statistical tests were two-sided. All analyses were performed using SAS software version 9.4 (SAS Institute, Cary, NC, USA).

\section{CONCLUSIONS}

Our study suggested a significant improvement of PFS and OS with continuation of trastuzumab in secondline chemotherapy for patients with HER2-positive advanced gastric or GEJ adenocarcinoma. The results support the concept of continuing the inhibition of the HER2 signaling pathway beyond progression, as already demonstrated in breast cancer. The low rate of HER2positive status in gastric cancer should encourage the development of international collaborations in order to confirm the utility of trastuzumab beyond progression through a large randomized phase III study.

\section{CONFLICTS OF INTEREST}

Dr Tougeron has participated in consulting or/and advisory boards for Amgen, Sanofi, Ipsen and Celgene; Dr Soularue for Novartis; Dr Ben Abdelghani for Sanofi, Amgen and Merck Serono; Dr Sarabi for Sanofi, Ipsen and Roche; Dr Evesque for Sanofi; Dr Hautefeuille for Lilly, Amgen, Merck Serono, Ipsen, Novartis, Pfizer and Sanofi; Dr Bouché for Merck Serono, Amgen, Roche, Lilly and Novartis; Dr Louvet for Celgene, Roche and Sanofi; Dr Lecomte for Lilly; Dr Taieb for Merck Serono, Sanofi, Roche, Pfizer and Amgen; Dr Zaanan for Merck Serono, Amgen, Roche, Sanofi and Lilly.

No other disclosures are reported. 


\section{REFERENCES}

1. Jemal A, Bray F, Center MM, Ferlay J, Ward E, Forman D. Global cancer statistics. CA Cancer J Clin. 2011; 61: 69-90. doi: 10.3322/caac.20107.

2. Wagner AD, Grothe W, Haerting J, Kleber G, Grothey A, Fleig WE. Chemotherapy in advanced gastric cancer: a systematic review and meta-analysis based on aggregate data. J Clin Oncol. 2006; 24: 2903-9.

3. Vanhoefer U, Rougier P, Wilke H, Ducreux MP, Lacave AJ, Van Cutsem E, Planker M, Santos JG, Piedbois P, Paillot B, Bodenstein H, Schmoll HJ, Bleiberg H, et al. Final results of a randomized phase III trial of sequential highdose methotrexate, fluorouracil, and doxorubicin versus etoposide, leucovorin, and fluorouracil versus infusional fluorouracil and cisplatin in advanced gastric cancer: A trial of the European Organization for Research and Treatment of Cancer Gastrointestinal Tract Cancer Cooperative Group. J Clin Oncol. 2000; 18: 2648-57.

4. Kang YK, Kang WK, Shin DB, Chen J, Xiong J, Wang J, Lichinitser M, Guan Z, Khasanov R, Zheng L, Philco-Salas M, Suarez T, Santamaria J, et al. Capecitabine/cisplatin versus 5-fluorouracil/cisplatin as first-line therapy in patients with advanced gastric cancer: a randomised phase III noninferiority trial. Ann Oncol. 2009; 20: 666-73. doi: 10.1093/annonc/mdn717.

5. Cunningham D, Starling N, Rao S, Iveson T, Nicolson M, Coxon F, Middleton G, Daniel F, Oates J, Norman AR. Capecitabine and oxaliplatin for advanced esophagogastric cancer. N Engl J Med. 2008; 358: 36-46. doi: 10.1056/ NEJMoa073149.

6. Van Cutsem E, Moiseyenko VM, Tjulandin S, Majlis A, Constenla M, Boni C, Rodrigues A, Fodor M, Chao Y, Voznyi E, Risse ML, Ajani JA. Phase III study of docetaxel and cisplatin plus fluorouracil compared with cisplatin and fluorouracil as first-line therapy for advanced gastric cancer: a report of the V325 Study Group. J Clin Oncol. 2006; 24: 4991-7.

7. Smyth EC, Verheij M, Allum W, Cunningham D, Cervantes A, Arnold D. Gastric cancer: ESMO Clinical Practice Guidelines for diagnosis, treatment and follow-up. Ann Oncol. 2016; 27: v38-v49.

8. Guimbaud R, Louvet C, Ries P, Ychou M, Maillard E, Andre T, Gornet JM, Aparicio T, Nguyen S, Azzedine A, Etienne PL, Boucher E, Rebischung C, et al. Prospective, randomized, multicenter, phase III study of fluorouracil, leucovorin, and irinotecan versus epirubicin, cisplatin, and capecitabine in advanced gastric adenocarcinoma: a French intergroup (Federation Francophone de Cancerologie Digestive, Federation Nationale des Centres de Lutte Contre le Cancer, and Groupe Cooperateur Multidisciplinaire en Oncologie) study. J Clin Oncol. 2014; 32: 3520-6. doi: 10.1200/JCO.2013.54.1011.
9. Boku N. HER2-positive gastric cancer. Gastric Cancer. 2014; 17: 1-12. doi: 10.1007/s10120-013-0252-z.

10. Bang YJ, Van Cutsem E, Feyereislova A, Chung HC, Shen L, Sawaki A, Lordick F, Ohtsu A, Omuro Y, Satoh T, Aprile G, Kulikov E, Hill J, et al. Trastuzumab in combination with chemotherapy versus chemotherapy alone for treatment of HER2-positive advanced gastric or gastro-oesophageal junction cancer (ToGA): a phase 3, open-label, randomised controlled trial. Lancet. 2010; 376: 687-97. doi: 10.1016/ S0140-6736(10)61121-X.

11. Gong J, Liu T, Fan Q, Bai L, Bi F, Qin S, Wang J, Xu N, Cheng Y, Bai Y, Liu W, Wang L, Shen L. Optimal regimen of trastuzumab in combination with oxaliplatin/ capecitabine in first-line treatment of HER2-positive advanced gastric cancer (CGOG1001): a multicenter, phase II trial. BMC Cancer. 2016; 16: 68. doi: 10.1186/ s12885-016-2092-9.

12. Ryu MH, Yoo C, Kim JG, Ryoo BY, Park YS, Park SR, Han HS, Chung IJ, Song EK, Lee KH, Kang SY, Kang YK. Multicenter phase II study of trastuzumab in combination with capecitabine and oxaliplatin for advanced gastric cancer. Eur J Cancer. 2015; 51: 482-8. doi: 10.1016/j. ejca.2014.12.015.

13. Ford HE, Marshall A, Bridgewater JA, Janowitz T, Coxon FY, Wadsley J, Mansoor W, Fyfe D, Madhusudan S, Middleton GW, Swinson D, Falk S, Chau I, et al. Docetaxel versus active symptom control for refractory oesophagogastric adenocarcinoma (COUGAR-02): an openlabel, phase 3 randomised controlled trial. Lancet Oncol. 2014; 15: 78-86. doi: 10.1016/S1470-2045(13)70549-7.

14. Thuss-Patience PC, Kretzschmar A, Bichev D, Deist T, Hinke A, Breithaupt K, Dogan Y, Gebauer B, Schumacher G, Reichardt P. Survival advantage for irinotecan versus best supportive care as second-line chemotherapy in gastric cancer--a randomised phase III study of the Arbeitsgemeinschaft Internistische Onkologie (AIO). Eur J Cancer. 2011; 47: 2306-14. doi: 10.1016/j.ejca.2011.06.002.

15. Hironaka S, Ueda S, Yasui H, Nishina T, Tsuda M, Tsumura T, Sugimoto N, Shimodaira H, Tokunaga S, Moriwaki T, Esaki T, Nagase M, Fujitani K, et al. Randomized, openlabel, phase III study comparing irinotecan with paclitaxel in patients with advanced gastric cancer without severe peritoneal metastasis after failure of prior combination chemotherapy using fluoropyrimidine plus platinum: WJOG 4007 trial. J Clin Oncol. 2013; 31: 4438-44. doi: 10.1200/ JCO.2012.48.5805.

16. Fuchs CS, Tomasek J, Yong CJ, Dumitru F, Passalacqua R, Goswami C, Safran H, dos Santos LV, Aprile G, Ferry DR, Melichar B, Tehfe M, Topuzov E, et al. Ramucirumab monotherapy for previously treated advanced gastric or gastro-oesophageal junction adenocarcinoma (REGARD): an international, randomised, multicentre, placebocontrolled, phase 3 trial. Lancet. 2014; 383: 31-9. doi: 10.1016/S0140-6736(13)61719-5. 
17. Wilke H, Muro K, Van Cutsem E, Oh SC, Bodoky G, Shimada Y, Hironaka S, Sugimoto N, Lipatov O, Kim TY, Cunningham D, Rougier P, Komatsu Y, et al. Ramucirumab plus paclitaxel versus placebo plus paclitaxel in patients with previously treated advanced gastric or gastrooesophageal junction adenocarcinoma (RAINBOW): a double-blind, randomised phase 3 trial. Lancet Oncol. 2014; 15: 1224-35. doi: 10.1016/S1470-2045(14)70420-6.

18. Bennouna J, Sastre J, Arnold D, Osterlund P, Greil R, Van Cutsem E, von Moos R, Vieitez JM, Bouche O, Borg C, Steffens CC, Alonso-Orduna V, Schlichting C, et al. Continuation of bevacizumab after first progression in metastatic colorectal cancer (ML18147): a randomised phase 3 trial. Lancet Oncol. 2013; 14: 29-37. doi: 10.1016/ S1470-2045(12)70477-1.

19. von Minckwitz G, du Bois A, Schmidt M, Maass N, Cufer T, de Jongh FE, Maartense E, Zielinski C, Kaufmann M, Bauer W, Baumann KH, Clemens MR, Duerr R, et al. Trastuzumab beyond progression in human epidermal growth factor receptor 2-positive advanced breast cancer: a german breast group 26/breast international group 03-05 study. J Clin Oncol. 2009; 27: 1999-2006. doi: 10.1200/ JCO.2008.19.6618

20. Cardoso F, Costa A, Senkus E, Aapro M, Andre F, Barrios $\mathrm{CH}$, Bergh J, Bhattacharyya G, Biganzoli L, Cardoso MJ, Carey L, Corneliussen-James D, Curigliano G, et al. 3rd ESO-ESMO International Consensus Guidelines for Advanced Breast Cancer (ABC 3). Ann Oncol. 2017 Feb 19. [Epub ahead of print].

21. Satoh T, Xu RH, Chung HC, Sun GP, Doi T, Xu JM, Tsuji A, Omuro Y, Li J, Wang JW, Miwa H, Qin SK, Chung IJ, et al. Lapatinib plus paclitaxel versus paclitaxel alone in the second-line treatment of HER2-amplified advanced gastric cancer in Asian populations: TyTAN--a randomized, phase III study. J Clin Oncol. 2014; 32: 2039-49. doi: 10.1200/ JCO.2013.53.6136.

22. Hecht JR, Bang YJ, Qin SK, Chung HC, Xu JM, Park JO, Jeziorski K, Shparyk Y, Hoff PM, Sobrero A, Salman P, Li J, Protsenko SA, et al. Lapatinib in Combination With Capecitabine Plus Oxaliplatin in Human Epidermal Growth Factor Receptor 2-Positive Advanced or Metastatic Gastric, Esophageal, or Gastroesophageal Adenocarcinoma: TRIO013/LOGiC--A Randomized Phase III Trial. J Clin Oncol. 2016; 34: 443-51. doi: 10.1200/JCO.2015.62.6598.

23. Kang YK, Shah MA, Ohtsu A, Van Cutsem E, Ajani JA, Van der Horst T, Harle-Yge ML, Piao Y, Althaus B,
Thuss-Patience PC. A randomized, open-label, multicenter, adaptive phase $2 / 3$ study of trastuzumab emtansine (T-DM1) versus a taxane (TAX) in patients (pts) with previously treated HER2-positive locally advanced or metastatic gastric/gastroesophageal junction adenocarcinoma (LA/ MGC/GEJC). J Clin Oncol. 2016; 34.

24. Li Q, Jiang H, Li H, Xu R, Shen L, Yu Y, Wang Y, Cui Y, Li W, Yu S, Liu T. Efficacy of trastuzumab beyond progression in HER2 positive advanced gastric cancer: a multicenter prospective observational cohort study. Oncotarget. 2016; 7: 50656-50665. doi:10.18632/oncotarget.10456.

25. Makiyama A, Shimokawa M, Kashiwada T, Takahashi I, Emi Y, Kusumoto T, Yamamoto K, Ishikawa H, Negoro Y, Oki E, Saeki H, Kakeji Y, Baba H, et al. Trastuzumab beyond first progression in cases of HER2-positive advanced gastric or gastro-esophageal junction cancer: Initial results from KSCC1105, a trastuzumab observational cohort study. Journal of Clinical Oncology. 2017; 35: 93.

26. Kim DY, Kim JH, Lee SH, Kim TY, Heo DS, Bang YJ, Kim NK. Phase II study of oxaliplatin, 5-fluorouracil and leucovorin in previously platinum-treated patients with advanced gastric cancer. Ann Oncol. 2003; 14: 383-7.

27. Arienti C, Zanoni M, Pignatta S, Del Rio A, Carloni S, Tebaldi M, Tedaldi G, Tesei A. Preclinical evidence of multiple mechanisms underlying trastuzumab resistance in gastric cancer. Oncotarget. 2016; 7: 18424-39. doi: 10.18632/oncotarget.7575.

28. Mao L, Sun AJ, Wu JZ, Tang JH. Involvement of microRNAs in HER2 signaling and trastuzumab treatment. Tumour Biol. 2016 Oct 12. doi: 10.1007/s13277-016-54053. [Epub ahead of print].

29. Pietrantonio F, Caporale M, Morano F, Scartozzi M, Gloghini A, De Vita F, Giommoni E, Fornaro L, Aprile G, Melisi D, Berenato R, Mennitto A, Volpi CC, et al. HER2 loss in HER2-positive gastric or gastroesophageal cancer after trastuzumab therapy: Implication for further clinical research. Int J Cancer. 2016; 139: 2859-64. doi: 10.1002/ ijc. 30408 .

30. Seo S, Ryu MH, Ahn JY, Park Y, Park SR, Ryoo BY, Park YS, Lee GH, Jung HY, Kang YK. Loss of HER2 positivity after anti-HER2 chemotherapy in HER2-positive gastric cancer patients: Results of GASTric cancer HER2 reassessment study 3 (GASTHER3). Journal of Clinical Oncology. 2017; 35: 27. 